\title{
Da Exacerbação dos Sentidos no Encontro com a Natureza: Contrastando Esportes Radicais e Turismo de Aventura
}

\author{
Mary Jane P. Spink ${ }^{1}$ \\ Sérgio Seiji Aragaki \\ Marina Pigozzi Alves \\ Pontificia Universidade Católica de São Paulo
}

\begin{abstract}
Resumo
Este artigo visa a contribuir para a compreensão do risco-aventura, entendido como o conjunto de práticas que recuperam a dimensão positiva dos riscos. Com base na revisão da literatura e apoiado na vertente construcionista da Psicologia Discursiva, propõe um modelo para análise das dimensões de risco-aventura presentes no turismo de aventura e nos esportes radicais: risco/perigo, adrenalina, aventura, treinamento, uso de equipamentos e relação com a natureza. Como fonte de dados, utilizamos o site de uma operadora especializada em turismo de aventura e uma entrevista com um praticante de parapente. Os dados coletados foram analisados utilizando árvores de associação de idéias e mapas dialógicos. Todos os elementos do modelo analítico se fizeram presentes nas duas modalidades de risco-aventura. Porém, o turismo de aventura caracterizou-se pela delegação do controle do risco a especialistas, enquanto que nos esportes radicais a dimensão treinamento/ experiência foi priorizada, enfatizando-se a responsabilidade individual no controle dos riscos.
\end{abstract}

Palavras-chave: Risco-aventura; linguagem dos riscos; produção de sentidos; turismo de aventura; esportes radicais.

Sensation Seeking in Outdoor Pursuits: Similarities and Differences in Discourses on Radical Sports and Adventure Tourism

\begin{abstract}
This article is a contribution to the understanding of risk-adventure as the set of practices that recuperate the positive dimension of risk. Based on a review of the literature and on the theoretical approach of Constructionist Discursive Psychology, it proposes a model for the analysis of the dimensions of risk adventure present in adventure tourism and radical sports: risk/danger, adrenaline, adventure, training, use of equipments and relationship to nature. The data, derived from the site of a tourism agency that specialized in adventure tourism and an interview with a paraglide practitioner, was analyzed using "trees of association of ideas" and "dialogical maps". All the elements of the model were present in both modalities of risk-adventure. However, adventure tourism was characterized by the delegation of responsibility to specialists, whilst the training/experience dimension made itself more present in radical sports, along with greater emphasis on individual responsibility in the control of risks.
\end{abstract}

Keywords: Risk-adventure; risk language; making sense; adventure tourism; radical sports.

Este artigo tem como objetivo contribuir para a compreensão dos diversos sentidos do risco-aventura, entendido como o conjunto de práticas que recuperam a aventura como dimensão positiva dos riscos que, contrapondo-se à perspectiva racionalizadora da análise dos riscos, constituem deslocamentos importantes dos sentidos dos riscos na sociedade contemporânea, conforme teorizações por nós feitas em outras publicações (Spink, 2000, 2001a, 2001b). Tendo por base dados coletados em pesquisas sobre risco ${ }^{2}$, busca, mais especificamente, estabelecer parâmetros para diferenciar o turismo de aventura (ou esportes na natureza), modalidade que vem sendo explorada em empreendimentos comerciais variados, e os esportes radicais, seja na modalidade mais institucional dos esportes competitivos, seja na forma de aventuras individuais.

Sabemos que há uma velha conexão entre risco e aventura, valorizada pela ousadia passível de levar a descobertas. Há também uma associação entre risco e aposta, em sua essência de potencialidade de ganhos e perdas, que deixou marcas profundas

\footnotetext{
${ }^{1}$ Endereço para correspondência: Programa de Estudos Pós-graduados em Psicologia Social. Pontifícia Universidade Católica de São Paulo, Rua Monte Alegre, 984, 05014 901, São Paulo. Fone, Fax: (11) 36708400. E-mail: mjspink@pucsp.br

${ }^{2}$ Projeto Integrado de Pesquisa apoiado pelo CNPq
}

no domínio da economia. Há, ainda, uma conexão entre risco e formação de caráter, expressa no valor educativo da aventura. Por exemplo, um dos mais antigos empreendimentos comerciais de educação por meio da aventura é o Outward Bound, com início em 1941, no País de Gales, Inglaterra. O objetivo desse projeto é treinar por meio do corpo, em oposição a treinar o corpo (Martin, 1994), sendo norteado por cinco valores: a) aventura e desafio; b) compaixão e serviço; c) aprendizagem por intermédio da experiência; d) desenvolvimento pessoal; e) responsabilidade social e ambiental. O Outward Bound teve imenso sucesso no pósguerra, estando hoje firmemente implantado em diversos países.

Entretanto, nos deparamos hoje com novas modalidades de aventura, seja na vertente dos esportes radicais, na perspectiva mais disciplinada do turismo de aventura ou, ainda, na busca da emoção exacerbada pelas drogas lícitas e ilícitas. Alguns autores (entre eles, Giddens, 1991; Le Breton, 1996) vêm procurando entendê-las à luz das características da sociedade de risco, situando-as como formas de anteparo aos processos de destradicionalização que acompanham a globalização.Temos assumido a posição que, para entendê-las, é preciso antes de tudo situá-las no contexto do tempo longo dos jogos. Optamos, para isso, pelas teorizações hoje clássicas de Roger Caillois (1958).

Caillois (1958) baseia seu modelo para compreensão dos jogos na intersecção de duas dimensões: as diferentes modalidades 
e o grau de disciplinarização. Propõe quatro modalidades básicas de jogos: competição (agôn); chance (alea); simulacro (mimicry); e vertigem (ilinx). As quatro modalidades aparecem em duas formas: uma mais espontânea (ou primitiva) - a paidia - e a outra mais regrada - o ludus. Podemos pensá-las na perspectiva da sociogênese, ou seja, a paidia como uma forma menos socializada dos jogos, típica, por exemplo, da infância e o ludus como a forma disciplinada, socializada e presa a regras de comportamento.

Um dos fenômenos mais surpreendentes da época atual é o crescimento quase desenfreado dos esportes na natureza, modalidades de jogos que se enquadram tanto no ilinx - por seu forte componente de vertigem - como no agôn, dado que muitas vezes assumem a forma organizada de desafios competitivos. É nesse contexto que situamos o risco-aventura.

Faz parte desse movimento de expansão a emergência de novas formas de esportes de ação na década de 1970, tendo como precursora a Whitbread Ocean Race, com início em 1973. Data também dessa época o surgimento de modalidades de riscoaventura que utilizam veículos motorizados, especialmente as disputas de veículos off-the-road, sendo as mais conhecidas o Rali Paris-Dakar, iniciado em 1979, e o Camel Trophy, realizado em lugares inóspitos em diferentes países, a partir de 1980.

O final dos anos 1980 vê emergir novas modalidades de riscoaventura: os ralis humanos. A primeira competição nessa nova modalidade teria sido o Raid Gauloise, concebido por um jornalista francês, Gérard Fusil, e realizado pela primeira vez na Nova Zelândia em 1989. Já o Eco-Challenge Lifestyles Inc., fundado por Mark Burnett em 1992, inova por associar aventura e ecologia. Trata-se, como seu antecessor, de uma competição de resistência que envolve múltiplas modalidades de esporte: montaria a cavalo, canoagem, escalada, rapel, mountain bike e longas caminhadas (ver definição das modalidades no Anexo A). Tem como ingredientes principais o trabalho em equipe, a resistência, o espírito de aventura e a compaixão, mesclados com a consciência ecológica, manifesta não só no respeito absoluto à natureza como também na ação ambiental efetiva apoiando iniciativas locais.

Para entender a multiplicidade de modalidades de risco-aventura na sociedade contemporânea é conveniente recorrer mais uma vez a Caillois (1958) e sua proposta de que o ludus pode ter formas culturais e institucionais. As formas culturais englobam todas as modalidades de esportes radicais que exaltam a velocidade, a adrenalina, a obliteração da razão pela concentração total na ação, por exemplo: o esqui, o alpinismo, o surfe e as diversas modalidades de esportes que envolvem desafio, sobrevivência e vertigem.

As formas institucionais se fazem presentes, sobretudo, no mercado emergente do turismo de aventura. A aventura, nessa interpretação, passa a ser incorporada ao cotidiano como estratégia de edificação, seja na modalidade de formação de caráter, seja na vertente do desenvolvimento da responsabilidade perante o ambiente. Por exemplo, as modalidades de aprendizagem de flexibilidade e decisão nos programas de treinamento e desenvolvimento, desenhados como recurso de treinamento alternativo e que combinam a emoção do esporte na natureza com o treinamento corporativo tradicional.
Caillois (1958) propõe ainda que há formas corrompidas dos jogos de vertigem em que a razão é obliterada. O caso prototípico é o das drogas psicotrópicas, sejam elas lícitas ou ilícitas. Essa é a forma de risco que David Le Breton (1996) chama de esmaecimento (blancheur). Trata-se do inverso da vertigem e do desafio - em que o risco é ativamente buscado - com a atração direcionada para o menos e não para o mais: longe de provocar a morte, há um doce abandono a ela por meio do álcool, da droga, da fuga ou da vagabundagem. Mas, no que diz respeito ao risco-aventura, as formas corrompidas englobariam os esportes radicais que exaltam o risco e desafiam a morte, por exemplo, o B.A.S.E jumping.

Neste artigo, interesse-nos, sobretudo, a onipresença do riscoaventura em suas formas culturais e institucionais, tomadas como formas de expansão dos processos de disciplinarização na modernidade tardia, ampliando-os para além de suas formas institucionais tradicionais. Essa apropriação do risco-aventura pelos processos de disciplinarização contemporâneos tem como principal indicador a transformação dos esportes na natureza em poderosos mobilizadores de uma complexa indústria, que engloba desde equipamentos sofisticados ao seu uso midiático. Como objetos de desejo, tornam-se produtos a serem vendidos e meios para o marketing de outros tantos produtos (Dearden \& Andressen, 1987).

\section{Os Sentidos do Risco como Aventura: Breve Incursão na Literatura sobre Risco-Desejado}

Ao utilizarmos o termo risco-aventura, referimo-nos apenas parcialmente às novas modalidades de aventura e aos novos usos de antigas modalidades de jogos de vertigem. Empregamos o termo composto risco-aventura para enfatizar um deslocamento importante dos sentidos modernos do risco que recuperam a aventura como dimensão positiva dos riscos.

Os teóricos do risco, como Machlis e Rosa (1990), buscam incorporar essa dimensão em seus esquemas tipificadores sob a denominação de risco desejado. O risco desejado refere-se às "atividades ou eventos que têm incertezas quanto aos resultados ou conseqüências, e em que as incertezas são componentes essenciais e propositais do comportamento" (p. 162). Acatam, assim, a impossibilidade de compreender risco apenas na perspectiva racionalizadora da análise de riscos, entendida como a triangulação entre cálculo, percepção e gerenciamento dos riscos.

Encontramos, na revisão bibliográfica, três vertentes de explicação sobre por que as pessoas buscam formas de recreação que envolvem risco: a abordagem psicológica de traços de personalidade; a teoria de Goffman (1972) sobre caráter, e a abordagem do flow de Csikszentmihalyi (1975) e de Mitchell (1983).

\section{$\mathrm{O}$ risco-desejado como traço de personalidade}

O risco-desejado vem sendo estudado na Psicologia como traço de personalidade que reflete a busca individual de sensações e experiências novas, variadas e complexas, e a disposição de correr riscos físicos e sociais para a realização dessas experiências. Insere-se em longa linhagem de escalas e testes de personalidade 
que buscam medir o que Zuckerman (1979) chamou de busca de sensação (sensation seeking).

Em agosto de 2000 foi publicado um número especial do Journal of Adolescence sobre comportamentos de risco. Fica óbvio nesse conjunto de artigos, especialmente no texto de Gullone e Moore (2000), que também nessa arena o componente riscodesejado vem sendo expandido para além dos comportamentos de risco tradicionais: fumar, beber e praticar sexo desprotegido, entre outros. As autoras abordam quatro tipos específicos de risco: thrill seeking (comportamentos arriscados, mas socialmente aceitáveis, como os esportes radicais); rebellious behaviors (que incluem os ritos de passagem típicos da adolescência, como fumar e beber); reckless behaviors (comportamentos passíveis de ter resultados negativos - como dirigir alcoolizado ou fazer sexo desprotegido - e que são usualmente inaceitáveis para os adultos) e os comportamentos anti-sociais (inaceitáveis tanto para os adultos, quanto para os próprios adolescentes).

Esse e outros artigos dessa coletânea buscam sair do enfoque intra-individual de personalidade como substrato do comportamento, ressignificando os comportamentos de risco no enquadre da interação. Abrem espaço, assim, para incorporar certos elementos do interacionismo social, a segunda abordagem aqui considerada.

\section{Fateful activities e a possibilidade de expressão do caráter}

Goffman (1972) define fateful activities como eventos que são simultaneamente conseqüentes (têm desfechos que se estendem para além do evento propriamente dito) e problemáticos (quando há um grau de incerteza quanto aos resultados). São ocasiões em que tanto as propriedades primárias (tais como persistência, equilibrio, etc.), como o caráter, são manifestados. O caráter, segundo o autor, engloba aspectos variados tais como coragem, galanteria, integridade e compostura. Alguns desses aspectos podem manifestar-se em momentos seguros e rotineiros da vida familiar e ocupacional. Outros, entretanto, só podem manifestar-se quando a prudência é descartada. Nos termos da teoria da ação de Goffman, as pessoas prudentes freqüentemente abrem mão de oportunidades para mostrar certos atributos de caráter que são expressos apenas nesses momentos fatídicos (fateful moments).

Decorre daí a busca de apostas práticas: "empreendimentos que são vistos como estando além do circuito normal, evitáveis se assim o desejamos, mas cheios de riscos dramáticos e de oportunidades. Isto é, de ação. Quanto maior o grau de fatefullness, mais séria será a ação" (Goffman, 1972, p. 260).

\section{A busca de sentido na vida por meio da experiência do flow}

Há uma outra vertente de estudos que associa a busca de sensação com a criatividade e com a procura de sentido para a vida. O riscodesejado, nesta vertente, tem efeitos edificantes. Essa é a corrente associada a Csikszentmihalyi, autor do influente livro Beyond Boredom and Anxiety, publicado originalmente em 1975.

Csikszentmihalyi (1975) introduziu o conceito de flow para se referir a um estado de concentração no qual as pessoas estão conscientes de suas ações, mas não da consciência que têm delas.
Esse conceito vem sendo amplamente utilizado na literatura sobre experiências em modalidades variadas de risco-aventura.

Nas experiências de flow a ação e a consciência se fundem; focalizam exclusivamente o momento presente. São ocasiões em que as pessoas não temem o futuro e nem pensam no passado. A satisfação e o prazer derivam dessa fusão. A experiência do flow desfaz-se sob o impacto da racionalização, definida como "a infusão do método científico, da sofisticação tecnológica e do gerenciamento racional" (Mitchell, 1983, p. 217). Esse autor refere-se, sobretudo, ao risco-aventura comercial, onde importantes aspectos da ação passam para o controle de monitores profissionais, esvaecendo a experiência de flow. Ou seja, quando mais regrada a ação, maior o componente de ludus e mais fugidia a sensação de flow.

Adotaremos, no restante deste texto, o termo adrenalina para nos referirmos à essa fusão entre ação e consciência, por ser esse o termo mais utilizado nas modalidades diversas de riscoaventura no contexto brasileiro.

A vertente voltada à compreensão da busca de sensações tem gerado interessantes estudos etnográficos sobre modalidades variadas de esportes radicais, entre eles: asa delta (Brannigan \& McDougall, 1983), pára-quedismo (Celsi, Rose \& Leigh, 1983) e rafting em corredeiras (Ex.: Arnould \& Price, 1993; Holyfield, 1999). Muitos desses estudos têm como preocupação central a oferta e o consumo de esportes de ação. Buscam, assim, entender os esportes radicais como produtos em oferta na sociedade contemporânea e, aliando-se aos estudos sobre consumismo, procuram desvendar a natureza da experiência propiciada por essas atividades, assim como o conjunto de fatores que sustentam seu uso continuado.

\section{Objetivos}

Esta pesquisa teve como objetivo contribuir para a compreensão dos diversos sentidos do risco-aventura, entendido como o conjunto de práticas que recuperam a aventura como dimensão positiva dos riscos. Tendo por base dados coletados em pesquisas sobre risco, buscou, mais especificamente, estabelecer parâmetros para diferenciar o turismo de aventura (ou esportes na natureza) e os esportes radicais, seja na modalidade mais institucional dos esportes competitivos, seja na forma de aventuras individuais.

\section{Método}

\section{Procedimentos}

Para servir de subsídio para a análise comparativa aqui proposta, foi desenvolvido um modelo analítico com base na revisão da literatura sobre risco e na análise do discurso de dois praticantes de esportes radicais (P1 e P2), alunos da Pontifícia Universidade Católica de São Paulo e voluntários para participação em uma oficina sobre risco (Spink \& cols., 2003).

Para a análise dos discursos sobre o turismo de aventura, utilizamos o material disponível no site de uma agência de turismo 
especializada nesse ramo de atividades. Optamos por concentrar nossos esforços em Brotas, por ser esse um município que tem liderança reconhecida na área de turismo de aventura e, dentre os serviços disponíveis, selecionamos uma operadora de turismo, escolhida por ser a mais antiga, a primeira empresa criada para promover o ecoturismo na região.

O primeiro passo de análise foi fazer uma descrição do site utilizando, para isso, a metodologia de árvores de associação de idéias, estratégia que busca visualizar o fluxo de associação de idéias de um dado enunciado (Spink \& Lima, 1999). Como segundo passo da análise, foi feita uma descrição da página inicial do site, buscando entender as estratégias mercadológicas adotadas para atrair a clientela, especialmente a maneira como eram apresentadas as atividades turísticas e a ênfase relativa no encontro com a natureza e emoção propiciada pelos esportes de aventura. A terceira etapa da análise focalizou a página específica de oferta de atividades, sendo feita uma análise de discurso com base na metodologia dos mapas dialógicos, estratégia analítica que tem duplo objetivo: dar subsídio para o processo de interpretação e facilitar a comunicação dos passos subjacentes ao processo interpretativo (Spink \& Lima, 1999).

Para a análise do discurso sobre risco-aventura na perspectiva dos esportes radicais, utilizamos a entrevista realizada com um rapaz de 23 anos, formado em Direito e praticante de vôo livre em parapente. A análise de semelhanças e diferenças apoiou-se na elaboração de mapas dialógicos (Spink \& Lima, 1999) elaborados com base nas categorias do modelo analítico

Em conformidade com as normas éticas referentes à realização de pesquisas com seres humanos (Resolução 196/1996, do Conselho Nacional de Saúde/Ministério da Saúde e Resolução 16/2000, do Conselho Federal de Psicologia), adotamos, como estratégia de proteção dos participantes desta pesquisa, a assinatura de Consentimento Informado. Os nomes dos participantes e da operadora de turismo foram omitidos para preservar o anonimato.

\section{Resultados}

\section{Sobre o Risco-Aventura e suas Diferentes Modalidades: Situando as Semelhanças e Diferenças entre Esportes Radicais e Turismo de Aventura}

A linguagem utilizada para falar sobre o risco-aventura ainda está em construção, mesclando terminologias e modalidades de atividades. Fala-se em esportes de ação, aventuras, esporte de aventura, esporte outdoor, esportes de alto risco, esportes perigosos (ou arriscados) e esportes radicais. A lista de atividades é longa e inclui modalidades que são desenvolvidas no ar, na terra e/ou na água. Muitas delas podem ser realizadas num continum de risco. Por exemplo, podemos passear de bicicleta ou usá-la (com os equipamentos apropriados) para desafiadoras aventuras em terrenos inóspitos.

Conseqüentemente, consideramos mais apropriado buscar uma definição abrangente de risco-aventura que incluísse os componentes que a literatura parece dar destaque ao referir-se ao risco, ao radicalismo ou à aventura: que envolvam o desafio aos limites físicos ou aos limites de nossas habilidades; que possam ser caracterizadas como fateful activities na acepção de Goffman (1972) — eventos que são simultaneamente conseqüentes e problemáticos — e que sejam passíveis de gerar a fusão entre ação e consciência, que Csikszentmihalyi (1975) denomina flow ou, ainda, a sensação de vertigem característica do ilinx (Caillois, 1958).

Essas atividades podem ser realizadas dentro ou fora de esquemas comerciais de aventura; podem envolver ou não competição e podem enfatizar mais especificamente algum dos componentes acima discriminados. Mas, de maneira geral, serão consideradas riscoaventura se envolverem desafios consideráveis (e até extremos) às habilidades, podendo gerar conseqüências pessoais graves (especialmente a morte) no caso de erro.

Recorreremos à entrevista com os praticantes de esportes radicais para situar o que vem a ser risco. A discussão, nesse momento, girava em torno da descrição de experiências de escalada do Pico da Neblina.

P1 ... quando a gente chegou lá tinha uma névoa absurda, não se via nada, tinha uma outra barraca com mais duas pessoas, dois rapazes também, a gente fez amizade muito grande, e dali a pouco chegou mais gente. Né? Mas, não tinha ninguém do IBAMA, não tinha: um guia ...

P2 E envolve um desafio, porque também uma das coisas legais é você sabendo que existe um risco e você passar por esse desafio sem acontecer nada com você. Então: você: escalar alguma montanha, ou fazer uma trilha, você sabe que você pode se machucar, tudo bem vai ter um apoio, mas o legal é você não se machucar, você vencer aquele desafio e: e sair inteiro daquilo lá, então: isso dá prazer também ... ${ }^{3}$

Buscando diferenciar as atividades desenvolvidas dentro de esquemas comerciais de risco-aventura, que denominaremos aqui turismo de aventura (também chamados de esportes na natureza), e esportes que buscam exacerbar os desafios físicos e/ou as habilidades técnicas, desenvolvemos uma classificação que incorpora sete categorias: o grau de risco/perigo; o componente de aventura; a necessidade percebida de habilidades e treinamento; a função dos equipamentos como estratégia de segurança; o uso de equipamentos para propiciar performance; a adrenalina e a relação com o meio ambiente.

Definimos risco como a probabilidade de ocorrência de um evento indesejável, como acidentes ou, no caso extremo, a morte. A aventura refere-se à busca de desafios relacionados com imponderabilidade e imprevisibilidade. O treinamento ou a experiência referem-se às habilidades prévias necessárias para desempenho da atividade em questão. Quanto aos equipamentos, buscamos diferenciar o seu uso para fins de segurança e sua função na modalidade específica de atividade, ou seja, sua relação com

${ }^{3}$ Todas as transcrições seguem as convenções da análise de discurso proposta por Potter \& Wetherell (1987) 


\begin{tabular}{|l|l|l|l|l|l|l|l|}
\hline & risco/perigo & aventura & $\begin{array}{l}\text { treinamento/ equipamento } \\
\text { experiência }\end{array}$ & $\begin{array}{l}\text { equipamento } \\
\text { como segurança } \\
\text { como } \\
\text { performance }\end{array}$ & $\begin{array}{l}\text { emoção/ } \\
\text { adrenalina }\end{array}$ & natureza \\
\hline $\begin{array}{l}\text { esportes } \\
\text { radicais }\end{array}$ & & & & & & & \\
\hline $\begin{array}{l}\text { turismo de } \\
\text { aventura }\end{array}$ & & & & & & \\
\hline
\end{tabular}

Figura 1. Contrastando turismo de aventura e esportes radicais de acordo com as dimensões do riscoaventura.

performance. No que diz respeito à emoção, partimos do pressuposto que o risco-aventura, em qualquer modalidade, tem a emoção como componente básico. Mas esta pode ser exacerbada por sua relação com os demais componentes do sistema de classificação aqui proposto. Por exemplo, não usar equipamentos de proteção propositadamente pode aumentar o risco da atividade e, conseqüentemente, o teor de adrenalina que se faz aí presente. Também o enquadre da atividade em cenários competitivos pode aumentar a emoção a ela associada. Finalmente, o meio ambiente, ou para sermos mais precisos, a natureza, pode ser mero palco das atividades ou um elemento central, como no caso de diversas modalidades de turismo de aventura. Na Figura 1 indicamos, por meio do sombreamento de células, o grau em que as diversas dimensões desse modelo estão presentes em atividades relacionadas com turismo de aventura e esportes radicais.

Essas diferentes dimensões das atividades relacionadas ao risco-aventura terão maior ou menor grau de controle pessoal dependendo do contexto da atividade. Quanto mais institucionalizada a atividade, mais o controle será delegado ou definido por outros, sejam eles os operadores que oferecem atividades de turismo de aventura ou os organizadores de competições; são eles que definem ou fornecem os equipamentos especializados, o tipo de equipamento de segurança a ser utilizado, roteiros e limites geográficos, etc. O grau de controle pessoal define, portanto, o grau de risco e aventura possíveis. Por exemplo, a opção de usar certos tipos de equipamentos de segurança, as possibilidades de ação relacionadas com o tipo de equipamento disponível (permitindo maior velocidade ou manobras mais arriscadas) ou, ainda, o contexto da ação (terrenos mais ou menos inóspitos, por exemplo).

Os entrevistados buscaram, em diversos momentos da entrevista, diferenciar esportes radicais e turismo de aventura, utilizando elementos do modelo descrito acima.

Sobre a transferência do risco para outra pessoa,

P1 ... Então, no: outro dia aí subiu, fez a trilha mais gente inclusive um grupo com guia. Né? E eu senti uma coisa, primeiro, o grupo com guia, por algum tempo a gente: fez a trilha junto com o pessoal [] E: você realmente fica numa posição passiva ali, você não age, você delega essa função de $<<$ Vamos nos localizar. Cadê a trilha? Onde tá isso? $>>$ e transfere também o risco para outra pessoa. $=$

Ainda sobre a aventura com guia,

$\mathrm{P} 2=$ É, o trekkeing, por exemplo, eu já fiz tanto com guia quanto sem ah:

(2.0) O do guia foi legal? Foi, mas o: o sem realmente é melhor que, porque: se você não tem alguém que está sendo responsável por você [] se você é a pessoa responsável tem muito mais esse lance do desafio de estar passando, no trekking com guia tinha alguns lugares que eu: [] que as pessoas tinham que passar, tudo bem isso aí tem o desafio de você estar passando, mas não tem aquilo de estar encontrando o caminho, de você ta (2.0) só por si. $=$

Sobre o diferencial introduzido pela competição,

P1 ... E que tem essa também, não a superação pessoal mas a superação em relação aos outros, né? A gente foi subir[

P2 [É o negócio da competição do trekking que: que estou fazendo ultimamente, não só passar pela trilha, mas como ser o: primeiro (?) Como: é uma de regularidade, não é o primeiro a chegar, mas é o primeiro na classificação geral, o que perdeu menos pontos tudo, então: tem uma coisa da competição. Que é o esporte, né? O esporte é isso, o esporte é competição.

Sobre risco e rafting,

P2 = Um que eu achei muito chato, que eu: eu não: considero como um esporte radical é o rafting, [ ] eu num senti risco no: rafting, sabe? Era: sabe? Colete salva vidas, que você tem que ter é claro, gente olhando qualquer coisa, se caiu na água já tem: alguém para jogar uma corda e tudo. É tão: [] é uma infra estrutura tão grande que você não: sente o risco. [] mas: é uma coisa que não me deu adrenalina por exemplo, eu não considero como esporte de risco [] você se sente muito protegido ali.

Fica claro, nessas falas, que a presença de um guia (ou instrutor) acarreta a diminuição da responsabilidade sobre as ações por parte do praticante, uma vez que o controle e o gerenciamento dos riscos fica ao cargo desses monitores. Por outro lado, como vimos, ser responsável pelas próprias ações intensifica o gosto pela competição, com o conseqüente aumento da sensação de desafio.

\section{O discurso sobre turismo de aventura: As operadoras de turismo de Brotas}

Considerando a tradição agropecuária e os recursos naturais - cachoeiras, matas preservadas e serras - a atual administração de Brotas, cidade localizada no interior do estado de São Paulo, junto com a população, vêm buscando fortalecer o setor turístico, visando uma alternativa de desenvolvimento sustentável para o município.

A operadora escolhida foi a primeira empresa criada para promover o ecoturismo na região, no enquadre do chamado 
desenvolvimento sustentável. Sendo a mais antiga, foi fruto do movimento organizado por moradores da região que haviam criado uma organização não-governamental - o Movimento Rio Vivo para proteger as águas do rio Jacaré Pepira, ameaçado pela cogitada instalação de uma indústria de curtume no município. Seu sucesso motivou o surgimento de diversas outras agências na região, transformando Brotas em uma das mais procuradas regiões para turistas que buscam esportes na natureza, sendo atualmente uma das referências nacionais na prática do ecoturismo.

Para entender as semelhanças e diferenças entre os esportes radicais e o turismo de aventura, objetivo desta pesquisa, buscamos analisar o discurso presente no site da operadora à luz das categorias definidas no modelo apresentado na Figura 1.

\section{A página de apresentação: O que vende a operadora}

A finalidade dessa descrição era entender as estratégias utilizadas pela operadora de turismo para atrair seu público, além de tentar identificar, por meio do formato da construção do seu site, qual é esse público e como o turismo de aventura é apresentado a essas pessoas.

Espacialmente, a página de abertura do site apresenta-se da seguinte maneira: à esquerda e no topo do site está o logotipo da empresa: o desenho de uma montanha, com cores claras e traços irregulares, que traz o nome da empresa. Logo abaixo se encontram links na seguinte ordem: Saiba mais; Atividades; Brotas; Acontece (com a programação mais recente); Curiosidades e As últimas (que possui um quadro com as últimas novidades da empresa).

Na coluna central, que se intitula Destaques da Operadora X, constam as características da empresa. Em proeminência, observa-se o anúncio da ISO 14001, uma ferramenta criada pela International Organization for Standards para auxiliar as empresas a identificar, priorizar e gerenciar seus riscos ambientais. Tendo em vista o objetivo maior desta operadora de desenvolver atividades de turismo no enquadre da preservação ambiental, entende-se o destaque dado à obtenção desse certificado.

Logo abaixo há links que anunciam atividades especiais como, por exemplo, as ofertas da temporada e aquelas voltadas a grupos de estudantes. Há ênfase na experiência da empresa, nos valores que a orientam, no comércio de equipamentos para a prática dos esportes de aventura e nos prêmios a ela concedidos, como o Prêmio Balanço Ambiental promovido pela Gazeta Mercantil. No final dessa coluna há uma foto da equipe de monitores da empresa. Há também outras fotos tendo por tema a natureza local e os equipamentos para a prática dos esportes.

A terceira e última coluna (da esquerda para a direita) é a que possui a maior quantidade de fotos, mostrando pessoas praticando os esportes oferecidos pela operadora e a natureza exuberante de Brotas. No topo desta coluna fica um informe sobre mais um prêmio concedido à empresa (Prêmio Henry Ford). Logo abaixo aparecem links de depoimentos, de contato com a empresa, de atividades oferecidas e novamente um informe sobre o seu enquadramento nas regras da ISO 14001. Ainda nesta coluna há um anúncio de um fotógrafo profissional e um último link, "Anuncie aqui", vendendo o espaço da página para a divulgação de outros serviços.

No formato da página de abertura há algumas características relacionadas ao objetivo da empresa de vender serviços relacionados com o turismo de aventura, sendo a competência ilustrada pelo grande número de menções às garantias que a empresa oferece, balizadas pela referência à ISO 14001 - que aparece duas vezes nesta página - e pelos anúncios de prêmios concedidos à empresa. Essas várias referências têm por função atestar a qualidade, responsabilidade e principalmente segurança dos serviços oferecidos.

Outra característica é a ênfase dada ao esporte de aventura na natureza (terminologia adotada pela operadora), apresentado como prática inovadora. Por exemplo, o rafting - principal esporte oferecido pela empresa - é apresentado destacando aspectos pouco convencionais: o rafting noturno e o rafting para crianças (incluindo foto de uma participante com seu equipamento de segurança).

As fotos da página de abertura dão destaque a dois aspectos importantes do ponto de vista da venda dos produtos oferecidos: o contato com a natureza e a segurança na prática dos esportes oferecidos. O primeiro aspecto é comunicado por fotos de paisagens de Brotas. A segurança, por sua vez, é pontuada duplamente: por meio de fotografias de pessoas praticando esportes portando seus equipamentos de segurança e pela apresentação dos monitores como guardiões da segurança e como modelos de práticas seguras, aparecendo nas fotos com seus próprios equipamentos de segurança.

De maneira geral, essa página busca instigar a curiosidade e o espírito de aventura de clientes potenciais e, concomitantemente, fornecer garantias de segurança. Em nenhum momento o risco de acidentes inerentes aos esportes de aventura é mencionado. Muito pelo contrário, a ênfase está nas práticas que garantem segurança: uso de equipamentos, monitores treinados, reconhecimento da qualidade dos serviços pela concessão de prêmios e certificados de qualidade. Em suma, a empresa propõe vender a aventura sem o risco; a adrenalina com segurança.

\section{Os esportes na natureza}

A oferta de serviços propriamente dita encontra-se no link "Atividades". Nessa página há um aviso, em destaque, informando que a empresa procura promover a segurança dos clientes, mas alertando que essas atividades não possuem risco zero de acidentes. O texto, na íntegra, afirma:

ATENÇÃO: 'Como qualquer outra atividade física, os esportes de aventura, caminhadas ou cavalgadas na natureza são atividades que não possuem risco zero de acidentes como lesões ou fraturas. Porém em função de toda experiência e estrutura operacional da Operadora X, os equipamentos de segurança da melhor qualidade, a experiência e dedicação bem como os treinamentos constantes de seus instrutores, os riscos são bastante reduzidos. Dessa forma, antes departicipar de cada uma dessas atividades éimportante se informar com o pessoal de atendimento ou mesmo nesta home-page de todos os seus detalhes e as regras de conduta garantindo assim sua satisfação total, sem surpresas. E boa aventura!! (ênfases no texto do site)

O menu de atividades está subdividido em quatro categorias: esportes de aventura (que inclui as modalidades mais radicais de 
Tabela 1

Freqüência das dimensões do risco-aventura nas atividades oferecidas pela operadora de turismo

\begin{tabular}{|c|c|c|c|c|c|c|c|}
\hline $\begin{array}{l}\text { Atividades } \\
\text { (conforme nomenclatura } \\
\text { adotada pela operadora de turismo) }\end{array}$ & $\begin{array}{l}\text { Risco/ } \\
\text { perigo }\end{array}$ & Aventura & $\begin{array}{l}\text { Treinamento/ } \\
\text { experiência }\end{array}$ & $\begin{array}{c}\text { Equip/ } \\
\text { segurança }\end{array}$ & $\begin{array}{l}\text { Equip/ } \\
\text { perform }\end{array}$ & $\begin{array}{l}\text { Emoção/ } \\
\text { adrenal }\end{array}$ & Meio Amb \\
\hline a. Introdução & 2 & 3 & 1 & 2 & - & - & 1 \\
\hline b. Esportes de aventura & - & 1 & - & 1 & - & 4 & - \\
\hline b1. Rafting & 6 & 4 & 1 & 14 & - & 1 & 2 \\
\hline b2. Rafting noturno & - & 3 & - & 2 & - & 1 & - \\
\hline b3. Mini rafting & - & 2 & - & 1 & - & - & - \\
\hline b4. Bóia cross & 1 & 3 & - & 14 & - & 2 & - \\
\hline b5. Duck/caiaque & - & & - & - & - & - & - \\
\hline b6. Canyoning/ rapel & 1 & 1 & - & 5 & - & 3 & 3 \\
\hline b7. Verticália & - & & - & 6 & - & - & - \\
\hline b8. Mountain bike & - & 1 & - & 1 & - & 1 & - \\
\hline c. Trekking & - & 1 & - & - & - & - & 1 \\
\hline c1. Trilha Santa Maria & - & - & - & - & - & - & 2 \\
\hline c2. Trilha Furna do Jacaré & - & - & - & - & - & - & 2 \\
\hline c3. Areia que canta & - & - & - & - & - & - & 1 \\
\hline c4. Trilha Morro da Sela & - & 1 & - & - & - & - & - \\
\hline c5. Cavalgada no paredão & - & - & 1 & - & - & - & 1 \\
\hline c6. Expedição Brotas adentro & - & 1 & - & - & - & 1 & - \\
\hline c7. City tour & - & 1 & - & - & - & - & 2 \\
\hline d. Estudos do meio & - & - & - & 4 & - & - & 14 \\
\hline e. Treinamentos & - & 4 & - & 3 & - & - & 2 \\
\hline Total & 10 & 26 & 3 & 53 & 0 & 13 & 31 \\
\hline
\end{tabular}

atividade como o rafting e o canyoning); o trekking (modalidades menos radicais, como trilhas e cavalgadas); os estudos do meio e os treinamentos. Ou seja, a própria operadora faz uma distinção baseada no grau de exposição a riscos nas atividades oferecidas.

\section{As dimensões do risco-aventura no discurso sobre as atividades oferecidas} pela operadora de turismo

As dimensões do risco-aventura descritas na Figura 1 foram analisadas com base no texto relativo a cada um dos esportes de aventura oferecidos no site da empresa. Para isso, transferimos as descrições das atividades para um mapa dialógico (Spink \& Lima, 1999) organizado em colunas definidas pelas dimensões de risco-aventura: risco/perigo; aventura; equipamentos/ segurança; equipamentos/performance; adrenalina e meio ambiente. A Tabela 1 fornece as freqüências de menções a cada uma das dimensões de risco-aventura.

$\mathrm{Na}$ descrição das atividades, três dimensões do riscoaventura aparecem com maior destaque: a segurança, a relação com o meio ambiente e a aventura. Como a operadora classifica as modalidades de turismo aventura em três categorias (esportes de aventura, trekking e estudos do meio), há interessantes diferenças na referência às atividades assim classificadas. Essas diferenças serão apontadas no decorrer da análise.

A segurança resulta de diversas estratégias: o uso de equipamento de segurança, a experiência e o treinamento dos monitores, a infra-estrutura (serviços de emergência e de pronto- socorro), assim como pelo seguro de vida obrigatório para os praticantes. Há 53 menções de estratégias de segurança, sendo elas mais freqüentemente mencionadas, como seria de esperar, nas referências aos esportes de aventura (na terminologia adotada pela operadora), com destaque para o rafting e o bóia cross. $\mathrm{O}$ conteúdo dos textos relativos à segurança parece ter como objetivo passar aos turistas potenciais a possibilidade de vivenciar a emoção dos esportes de aventura sem incorrer em riscos. Pontua-se que "não há risco zero", mas que a probabilidade destes ocorrerem é remota, dada a qualidade do equipamento e a experiência da equipe de suporte (os monitores). Não há menção às habilidades ou treinamentos necessários para a prática dessas atividades, mesmo porque essa responsabilidade é delegada aos instrutores qualificados.

Em nítido contraste, as atividades listadas sob o trekking mencionam pouco as questões relacionadas à segurança e enfatizam mais o contato com o meio ambiente e a beleza do cenário. O mesmo acontece com as atividades relacionadas com os estudos do meio, categoria que apresenta o maior número de menções ao meio ambiente com ênfase na preservação ambiental, sobretudo no que diz respeito à limpeza dos recursos hídricos.

Vale apontar que foi isso que motivou a criação da ONG Movimento Rio Vivo, à qual está associada à operadora. Talvez isso explique a menção aos modos de relação com a natureza no enquadre do desenvolvimento sustentável em praticamente todas as páginas do site, não se restringindo às descrições das atividades 
oferecidas pela agência. Os textos abordam, de um lado, a responsabilidade da empresa em relação ao meio ambiente local; de outro, dão destaque para a beleza das paisagens locais que tornam as atividades de turismo de aventura mais prazerosas para os clientes.

Como vimos, a dimensão da aventura também tem destaque, parecendo servir de contraponto à dimensão da segurança. Sabemos que, ao se enfatizar a necessidade da segurança, está se reconhecendo, mesmo que implicitamente, a existência de riscos associados aos esportes de aventura. A categoria aventura parece balizar o excessivo controle das estratégias de segurança, fazendo um apelo ao espírito de aventura. A aventura é também muitas vezes descrita em termos de emoções, valendo-se de referências bastante freqüentes à adrenalina. Tais referências se restringem basicamente às descrições dos esportes de aventura (terminologia adotada pela operadora), sendo digna de destaque a observação quanto à introdução do canyoning na Expedição Brotas Adentro. Diz o texto:

Longe das cidades, isolados na natureza, dois dias explorando e curtindo as ricas paisagens, aventuras e histórias do Vale do Rio do Peixe. Caminhando, cavalgando, adrenalizando [grifo no site] no Canyoning, ou relaxando em volta de uma fogueira, junto dos novos amigos e com as estrelas como teto.

Em suma, coerente com o modelo proposto, o turismo de aventura é apresentado como uma atividade segura, onde os riscos são minimizados por estratégias de segurança diversas, com delegação da responsabilidade pelas habilidades técnicas necessárias para a realização da atividade a especialistas. Ou seja, a emoção da aventura com cinto de segurança. Dentre as muitas manifestações de clientes encontradas no site da empresa são freqüentes os textos que apontam essa duplicidade: adrenalina/ emoção e segurança: "Vocês da Operadora X estão de parabéns pela ótima equipe de profissionais, trabalhando sempre com segurança e proporcionando aos turistas momentos de muita adrenalina ...” (T. L., 12/12/01).

Risco e segurança nos esportes radicais: $O$ caso do parapente

De modo a entender as dimensões do risco-aventura na perspectiva dos esportes radicais, tomaremos como exemplo a prática de vôo livre em parapente. O vôo livre é uma prática desportiva regulamentada e fiscalizada pelo Departamento de Aviação Civil (DAC) do Ministério da Aeronáutica, e compreende as modalidades asa delta e parapente. Começou a ser praticado em nosso país em julho de 1974, tendo sido organizado, já em novembro de 1975, o $1^{\circ}$ Campeonato Brasileiro de Vôo Livre; em 1976 ocorreu a primeira participação de pilotos brasileiros em campeonato mundial.

Em Dezembro de 1975 foi fundada a Associação Brasileira de Vôo Livre (ABVL - http://www.abvl.com.br) que, segundo dados obtidos em 2002, é única responsável oficial de representação do vôo livre praticado no Brasil perante as autoridades aeronáuticas e desportivas em nível nacional e internacional.
O parapente começou a ser praticado no Brasil na metade da década de 1980, a partir das adaptações de equipamentos feitas por alguns pára-quedistas. Em 1989 ocorreu o $1^{\circ}$ Campeonato Brasileiro de Parapente, sendo que no mesmo ano uma equipe brasileira participou de campeonato mundial. Em 2002 foi criada a Associação Brasileira de Parapente (ABP - http:/ / www.abp.esp.br), a qual busca se tornar a entidade que representa o parapente em nível nacional.

Trata-se de um esporte onde o praticante decola a partir do salto de uma rampa localizada no alto de uma montanha ou sendo rebocado por um guincho, ganhando assim altura. Permanecendo sentado durante o vôo, utiliza uma asa não rígida, inflável, além de equipamentos de segurança (tais como capacete, pára-quedas reserva e proteção para a coluna) e, freqüentemente, um rádio comunicador.

O parapente permite um vôo de algumas horas, e um deslocamento de longas distâncias (recorde atual $425 \mathrm{~km}$ ), sendo que para isso o piloto aproveita as correntes de ar quente e o vento, o que implica estabelecer uma rota de vôo e analisar as condições meteorológicas locais. Para a prática é necessário ser maior de dezoito anos, submeter-se a exame médico que comprove inexistência de doença impeditiva e realizar treinamento e capacitação em escolas credenciadas para obtenção de carteira de piloto, renovável anualmente. Esse esportista pode, dependendo de seu tempo de prática, quantidade de vôos e competência comprovada por outros pilotos de maior graduação, entre outras exigências, alcançar níveis superiores dentro da categoria. Estes vão do nível I ao nível $\mathrm{V}$, além de possibilidades de ser instrutor (A, B ou C), examinador, etc.

De forma a entender os sentidos de risco e segurança no âmbito dos esportes radicais, foi realizada uma entrevista com um rapaz de 23 anos, recém-formado em Direito, que trabalhava na área de Direito Empresarial, mais especificamente com Direito Societário (constituição de empresas no Brasil, alteração de contrato social de empresas, questões relacionadas com propriedade intelectual e tecnologia ligada à informática). O interlocutor, que pratica o esporte há dois anos, fez um curso de vôo livre na modalidade parapente, estando classificado como nível II. Neste nível os praticantes estão capacitados para utilizar uma vela que possibilita o alcance de uma velocidade de aproximadamente 40 quilômetros por hora e um vôo de cerca de uma hora e meia.

De modo a permitir comparar as múltiplas dimensões do risco com aquelas encontradas no turismo de aventura, seguimos os mesmos procedimentos para construção dos mapas dialógicos para análise das práticas discursivas. Essa estratégia analítica gerou o quadro síntese apresentado no Anexo B, que utilizou sombreamento de caselas do mapa, omitindo-se o conteúdo das falas, para melhor visualização da freqüência de utilização das diversas dimensões do risco-aventura na construção discursiva. Trata-se apenas de uma indicação de relevância, uma vez que os discursos presos a cada dimensão tinham duração bastante diversa. Mas, de modo geral, as dimensões mais presentes são também as que têm maior verbalização, como poderá ser visto, a seguir, na análise detalhada de dois trechos da entrevista.

Predominaram, nesta entrevista, as explicações e descrições sobre riscos (24 ocorrências), treinamento e experiência (14 
ocorrências), adrenalina (11 ocorrências) e a segurança na perspectiva dos equipamentos (10 ocorrências). Em certa medida, essa distribuição reflete o foco da própria entrevista, que buscava entender a relação entre risco e adrenalina na prática de esportes radicais. Entretanto, grande parte da entrevista se centrou na descrição da prática propriamente dita, o que possibilitaria a emergência de outras dimensões, como a relação com a natureza e o status dos equipamentos como fatores que propiciam a performance e até mesmo o prazer estético a eles associados.

Foi interessante observar que as dimensões que se fizeram mais presentes não foram abordadas de forma independente. Algumas delas estão em óbvia relação. Assim, o risco é a contrapartida da adrenalina, especialmente no que concerne os desafios relacionados à performance e à competição. De forma semelhante, ao falar dos riscos, o entrevistado abordou os fatores que propiciam segurança: o treinamento e experiência, de um lado; o cuidado com o bom estado do equipamento, de outro.

Para melhor ilustrar essas questões foram selecionados alguns trechos da entrevista. O primeiro refere-se à escolha desse esporte. A linha de argumento co-construída na interação entre entrevistado $(\mathrm{P})$ e entrevistador $(\mathrm{C})$ inicia-se com uma explicação sobre a busca da adrenalina, e segue apontando que, "por mais louco que possa parecer, esse é um esporte seguro, uma coisa bem calculada".

P Então, quando eu cresci mais, eu quis fazer alguma coisa que desse um pouco mais adrenalina, um pouco mais emocionante (4).

$\mathrm{C}$ De adrenalina? $=$

$\mathrm{P}=$ Exatamente (2.0) Fazer vôo livre parece uma coisa muito louca, assim, que o pessoal se joga na montanha (1.0) não é bem assim. A adrenalina existe sim, mas é uma coisa muito bem calculada também, é um esporte muito (2.0) muito técnico, você tem que checar um milhão de coisas, não é uma coisa que você faz na loucura, você chega na rampa e fica uns vinte minutos checando ...

A segurança emerge, portanto, da checagem cuidadosa do equipamento e do exame das condições atmosféricas. Segue uma descrição dos riscos envolvidos e da importância das características técnicas do equipamento para fazer frente a esses riscos. Segundo o entrevistado, no caso de colapso da vela (a asa inflada utilizada nesse esporte), há um pára-quedas de reserva. Entretanto, seu uso também implica riscos.

P No caso específico do parapente, acontece o seguinte: a asa não é rígida, ela é inflada [ ] por exemplo, se você passa atrás de outro parapente, dependendo do (4.0) forma rotores atrás, o vento não continua fluindo na direção que ele veio até o parapente, ele começa a fazer reviravoltas, faz o que a gente chama de rotor, isso pode fazer com que sua vela feche, nessa você pode entrar em colapso no ar, a vela pode realmente fechar (3.0)

$\mathrm{CE}$ aî $=$

$\mathrm{P}=$ E aí você cai (2.0) ((risos)) Vocêt tem um pára-quedas reserva, também.[ C [Hã[

P [Nesse caso, você pode acionar, mas (2.0) mas o problema é que você não tem controle nenhum sobre o pára-quedas reserva (3.0)

C Sei:

$\mathrm{P}$ [tem o risco aí de você (2.0) não fazer uma aterrissagem suave, cair num lugar que você não possa ser resgatado, se chocar contra a pedra, porque no geral você tá perto de uma montanha, né.
Curiosamente, os riscos são também vistos como elementos importantes do esporte e o parapentista os usa para o desenvolvimento de manobras complexas e arriscadas, em vez de buscar evitá-los.

P [Então, é sempre esse risco que tem. Ou um vento muito forte e você subir, por exemplo, se você chega numa cúmulus nimbus, você nunca pode abrir um pára-quedas reserva, você corre o risco de ser sugado pra dentro da nuvem $=$

$\mathrm{C}=\mathrm{Ah}$, é? $=$

$\mathrm{P}=\mathrm{E}$. E esse é um risco grande. Tem até manobras, que se chama fullstall. Você tá chegando numa nuvem, você simplesmente fecha a sua vela, e espera cair, tenta cair, às vezes você não consegue nem cair, você (3.0) a velocidade de ascendência é de vinte metros por segundo, então você corre risco de ser jogado, a nuvem é um tufão, né, aquilo ali é um tufão ambulante, corre o risco de ficar preso lá dentro.

O entrevistado busca explicar a dinâmica entre ficar receoso e ficar estimulado, concluindo que é preciso conciliar o estímulo com a racionalidade que o esporte exige:

P [daí tem aquela parte que você tem que conciliar as duas coisas, o estímulo que você tá sentindo com o racional, porque você tem que checar um milhão de coisas [ ] então você tem que dar aquela checada, tem que tá consciente daquilo, tem que tá prestando atenção, e: e por outro lado, cê tá querendo decolar também, então tem que controlar as duas coisas.

Essa racionalidade concerne checar múltiplas coisas para poder então se dar o luxo de abandonar-se ao estímulo. A dificuldade surge quando as condições de tempo mudam de ruins para boas e as pessoas querem decolar, prestando menos atenção à checagem minuciosa do equipamento.

P ... O que acontece muito também, é do vento tá muito ruim, e de repente ficar bom, então todo mundo quer decolar[

C [Há, há[

$\mathrm{P}$ [nessa hora você tem que tomar cuidado, às vezes a pessoa deixa de checar porque acha que tá bom e vai correr pra decolar e não tá bom, e pode correr o risco.

Em suma, diferentemente dos discursos sobre turismo de aventura, a atração dos esportes radicais parece situar-se na dialética entre risco e adrenalina. A aventura tem pouco espaço porque a segurança exige a presença da racionalidade e cálculo. A relação com a natureza também tem conotações distintas, sendo menos pautada pela exacerbação da relação responsável com o meio ambiente, dentro de uma perspectiva ecológica. A natureza é, no caso, o pano de fundo para o esporte, apesar de que estar na natureza é fator importante na escolha dessa modalidade de atividade. A dimensão treinamento/ experiência se faz presente de forma muito contundente, sendo enfatizada a responsabilidade individual e havendo pouca dependência em agentes externos.

\section{Discussão e Considerações Finais}

Partindo do entendimento de que há uma dimensão positiva no enfrentamento de riscos e elegendo como foco de estudo a 
onipresença do risco-aventura em suas formas culturais e institucionais, tomadas como formas de expansão dos processos de disciplinarização na modernidade tardia, buscamos neste artigo explicitar as semelhanças e as diferenças nos discursos sobre esportes radicais e turismo de aventura.

Utilizamos material discursivo obtido em várias fontes: entrevistas em grupo, entrevista individual e informações derivadas de sites da internet. Todas essas formas discursivas são exemplos de linguagem em uso e indicadores dos repertórios lingüísticos que circulam em nossa sociedade. Têm, nesses repertórios, seus elos de ligação.

Há, sem dúvida, dinâmicas interacionais diferenciadas: interações face-a-face (no caso das entrevistas) e interações mediadas (no caso dos sites). Também a forma de endereçamento é distinta: clientes potenciais no caso do site, pesquisadores no caso das entrevistas. Essas diferenças teriam conseqüências no caso da análise dos processos de co-construção de sentidos. Mas, na medida em que o foco da análise é a presença das dimensões do risco-aventura tomadas na perspectiva dos repertórios lingüísticos disponíveis para argumentar sobre uma determinada prática esportiva, consideramos apropriado o uso de materiais tão diversos.

Assim, a despeito das diferenças quanto a endereçamento e dinâmica interacional, tomamos esse material discursivo como exemplo de práticas discursivas correntes no cotidiano de nossa sociedade e o analisamos utilizando árvores de associação de idéia e mapas dialógicos de modo a poder entender as diferenças e semelhanças no que concerne as dimensões de risco-aventura.

Partimos do pressuposto que estas características servem como fatores de atração ou rejeição por parte de potenciais praticantes e moldam práticas de sociabilidade bastante diferenciadas. Consideramos, sobretudo, que a compreensão dessas semelhanças e diferenças decorre menos das características intrínsecas das atividades do que das estratégias de governamentalidade que suscitam por estarem inseridas em contextos de práticas específicos.

Trabalhamos, nesta pesquisa. com uma definição abrangente de risco-aventura que incluiu os componentes que a literatura parece dar destaque ao referir-se ao risco, ao radicalismo ou à aventura: que envolvam o desafio aos limites físicos ou aos limites de nossas habilidades; que sejam simultaneamente conseqüentes e problemáticos, e que possam gerar a fusão entre ação e consciência que vem sendo denominada "adrenalina".

Nesta acepção, as atividades relacionadas ao turismo de aventura e esporte radicais implicam desafios consideráveis e até extremos às habilidades que podem gerar conseqüências pessoais graves no caso de erro. Em todas as atividades há um certo grau de risco/perigo, de adrenalina e de aventura; há necessidade de habilidades específicas e de algum treinamento, além de requererem o uso de equipamentos (pelo menos para garantir a segurança dos praticantes) e terem a "natureza" como cenário privilegiado. Porém, encontramos diferenças entre o turismo de aventura e os esportes radicais na exacerbação ou não desses componentes, assim como na sua utilização ou na sua centralidade.
Vale apontar, ainda, que, pelo fato da operadora de turismo classificar suas atividades em três tipos de modalidades (esportes de aventura, trekking e estudos do meio), foram encontradas diferenças também no âmbito do que denominamos genericamente de turismo de aventura. Em síntese, há mais semelhanças entre os esportes de aventura, na terminologia adotada pela operadora estudada, e o discurso do parapentista do que entre estes e as demais atividades oferecidas pela operadora. Nestas, a menção a risco/perigo, aventura e emoção/ adrenalina encontram-se minimizados.

Mas, por tratarem-se de atividades de cunho comercial, geridas, portanto, pelas normas estabelecidas pela Embratur e sujeitas aos parâmetros da responsabilidade civil no caso de danos aos clientes, encontramos diferenças entre os discursos relativos aos esportes de aventura e os de praticantes de esportes radicais (incluindo aí o praticante de parapente e os dois participantes da oficina sobre risco). Tais diferenças são mais claramente entendidas se pensadas na ótica da segurança, com ênfase em dois aspectos: a função dos equipamentos e a necessidade de treinamento específico. A função dos equipamentos é prover segurança; seu uso para potencializar performance é pouco enfatizado. O treinamento requerido é mínimo, ficando restrito, conforme amplamente apontado na literatura citada, a algumas poucas instruções sobre procedimentos; o controle dos riscos é delegado aos instrutores, que são apresentados com base na sua experiência e competência. Assim, argumenta-se na promoção desses serviços, que se trata de uma atividade bastante segura, onde os riscos encontram-se minimizados por estratégias de segurança diversas. A principal meta, é o encontro com a natureza, proporcionando um contato extremamente prazeroso e edificante ao praticante.

Em contraste, nos esportes radicais, o risco é exacerbado; ou seja, são altas as probabilidades de ocorrência de eventos indesejáveis, tais como acidentes ou até mesmo a morte do praticante. Intensificase, assim, a emoção/adrenalina; isto é, ao praticar uma atividade marcada pela imponderabilidade e pela imprevisibilidade dos riscos, obtém-se emoção/adrenalina diretamente proporcional. Também nessa modalidade de atividade os riscos constituem elementos importantes, mas, ao invés do esportista evitá-los, ele vai à sua busca e usa-os para o desenvolvimento de manobras complexas e arriscadas. A natureza é, no caso, o pano de fundo, se bem que estar nela inserido é fator importante da escolha dessa modalidade de esporte.

A segurança emerge da experiência e do treinamento do praticante, assim como da checagem cuidadosa do equipamento e do exame das condições atmosféricas. Ou seja, a dimensão treinamento/ experiência se faz presente de forma muito contundente, sendo enfatizada a responsabilidade individual e havendo pouca dependência em agentes externos. Talvez decorra daí a exacerbação dos sentidos na prática dos esportes radicais e a tendência de seus praticantes a menosprezar o turismo de aventura.

Tais diferenças se formatam em um cenário marcado também por semelhanças. Vale apontar, como elemento para discussão, que trabalhamos, nesta pesquisa, com as formas culturais e 
institucionais de risco-aventura, tomadas como ilustração de expansão dos processos de disciplinarização na modernidade tardia. Essa apropriação do risco-aventura pelos processos de disciplinarização contemporâneos tem como principal indicador a transformação dos esportes de aventura em poderosos mobilizadores de uma complexa indústria, que engloba desde equipamentos sofisticados ao seu uso midiático como meio para o marketing de outros tantos produtos. Como produtos a serem consumidos, envolvem custos consideráveis. Circulando amplamente na forma de anúncios ou matérias jornalísticas, tornam-se objetos de desejo também para parcelas da população que não tem acesso a essas formas de lazer. A atualização desse desejo é problemática. Em sua positividade, envolve atividades perpassadas por riscos, como o "surfe-urbano" no topo de trens e ônibus. Mas propicia o deslocamento para formas corrompidas de risco-aventura, na acepção de Le Bon (1979), passíveis de alimentar o ciclo de violência que vimos testemunhando nas sociedades urbanas contemporâneas. Esse aspecto precisa ser explorado em futuras pesquisas.

\section{Referências}

Arnould, E. J. \& Price, L. L. (1993). River magic: Extraordinary experience and the extended service encounter. Journal of Consumer Research, 20, 24-45.

Brannigan, A. \& McDougall, A. (1983). Peril and pleasure in the maintenance of a high risk sport: A study of handgliding. Journal of Sport Behavior, 6, 37-51.

Caillois, R.(1958). Les jeux et les hommes. Paris: Gallimard.

Celsi, R. L., Rose, R. L. \& Leigh, T. W. (1983). An exploration of high-risk leisure consumption through skydiving. Journal of Consumer Research, 20, 1-23.

Csikszentmihalyi, M. (1975). Beyond boredom and anxiety. San Francisco: Jossey-Bass.

Dearden, P. \& Andressen, B. (1987). Outdoor recreation in advertising: Changes in time, activities and products. Journal of Leisure Research, 19, 41-60.
Giddens, A. (1991). Modernity and self-identity. Cambridge, UK: Polity Press.

Goffman, E. (1972). Where the action is. Em E. Goffman (Org.), Interaction ritual (pp. 149-270). Middlesex, England: Penguin Books. (Original publicado em 1967)

Gullone, E. \& Moore, S. (2000). Adolescent risk-taking and the five-factor model of personality. Journal of Adolescence, 23, 392-407.

Holyfield, L. (1999). Manufacturing adventure: The buying and selling of emotions. Journal of Contemporary Ethnography, 28, 3-32.

Le Breton, D. (1996). Passions du risque. Paris: Métailié.

Machlis, G. E. \& Rosa E. A. (1990). Desired risk: Broadening the social amplification risk framework. Risk. Analysis, 10, 161-168.

Martin, E. (1994). Flexible bodies. Boston, Mass: Beacon Press.

Mitchell Jr., R. G. (1983). Mountain experience: The psychology and sociology of adventure. Chicago: University of Chicago Press.

Potter, J. \& Wetherell, M. (1987). Discourse and social psychology. London: Sage.

Spink, M. J. (2000). Risco e psicologia: O foco nos comportamentos de risco. Em A construção social do risco no cenário da AIDS (pp. 1-31). Relatório de Pesquisa, Brasilia: CNPq.

Spink, M. J. (2001a). Contornos do risco na modernidade reflexiva: Contribuições da psicologia social. Psicologia e Sociedade, 12, 156-173.

Spink, M. J. (2001b).Trópicos do discurso sobre o risco: Risco-aventura como metáfora na modernidade tardia. Cadernos de Saúde Pública, 17, 1277-1311.

Spink, M. J. \& Lima, H. (1999). Rigor e visibilidade: A explicitação dos passos da interpretação. Em M. J. Spink (Org), Práticas discursivas e produção de sentidos no cotidiano: Aproximações teóricas e metodológicas (pp. 93-122). São Paulo: Cortez.

Spink, M. J., Passarelli, C., Aron, M., Alves, M. P., Garcia, M. \& Moura, O. (2003). Ao sabor dos riscos: Reflexões sobre a dialogia e co-construção de sentidos. Em M. J. Spink (2003), Psicologia Social e Saúde: Práticas, saberes e sentidos (pp. 295-323). Petrópolis, RJ: Vozes.

Zuckerman, M. (1979). Sensation seeking + beyond the optimal level of arousal. Hillsadale, New Jersey: Erlbaum.

Sobre os autores

Mary Jane P. Spink é Professora Titular do Programa de Estudos Pós-graduados em Psicologia Social da Pontifícia Universidade Católica de São Paulo.

Sérgio Seiji Aragaki é Psicólogo, Doutorando do Programa de Estudos Pós-graduados em Psicologia Social da Pontifícia Universidade Católica de São Paulo.

Marina Pigozzi Alves é Bolsista de Iniciação Científica, CNPq. Faculdade de Psicologia, Pontifícia Universidade Católica de São Paulo. 


\section{Anexo A}

\section{Modalidades de turismo aventura mencionadas no texto}

Modalidade

Asa-delta (handgliding)

B.A.S.E Jumping

Bóia-cross

Canyoning

Mountain Bike

Parapente

Pára-Quedismo

(sky-diving)

Rafting

Rapel

Trekking

(caminhada)
Definição

Vôo livre com o auxílio de uma espécie de asa usualmente constituída de lona e fibra de carbono.

BASE. quer dizer Building (prédio), Antenna (antena), Span (ponte), e Earth (montanha). Ou seja, saltar de pára-quedas sem estar em voando. A maioria dos saltos é realizada de alturas muito baixas, o que aumenta o risco de forma exponencial.

Atividade turística de descer rios utilizando uma câmara de ar de caminhão amarrada de forma a deslizar sobre a água, levando apenas uma pessoa por bóia. A descida do rio e feita em grupos.

Técnicas de escalada, típicas do montanhismo, usadas para a investigação de cursos de rios, canyons e cachoeiras.

Percorrer trilhas de montanhas ou estradas de terra com bicicleta, num percurso que diversos tipos de obstáculos.

Salto com o parapente já aberto que acontece a partir de encostas (montanhas, falésias, dunas, etc). Parapente é uma asa não-rígida, flexível e mantida nesta conformação pela pressão aerodinâmica.

Os praticantes são conduzidos em uma aeronave até uma certa altura e, de lá, lançam-se no ar, abrindo o pára-quedas após alguns segundos.

Descidas em corredeiras de rios em botes infláveis, onde a participação de todos os componentes do bote é fundamental para o sucesso da aventura.

Técnica de descida vertical, na qual se desliza de forma controlada, usando cabos, vencendo obstáculos, tais como: cachoeiras (canyoning), prédios, paredões, abismos, penhascos, pontes, declives, etc.

Prática de percorrer áreas selvagens ou trilhas a pé, com percursos longos e de vários graus de dificuldades. 


\section{Anexo B}

Dimensões do risco-aventura na prática do parapente: síntese da análise dialógica

\begin{tabular}{|c|c|c|c|c|c|c|}
\hline Risco/Perigo & Aventura & $\begin{array}{l}\text { Treinamento/ } \\
\text { Experiência }\end{array}$ & $\begin{array}{l}\text { Segurança } \\
\text { (equipamento e } \\
\text { outras } \\
\text { estratégias) }\end{array}$ & $\begin{array}{l}\text { Equipamentos } \\
\text { como } \\
\text { performance }\end{array}$ & $\begin{array}{l}\text { Emoção/ } \\
\text { Adrenalina }\end{array}$ & Meio ambiente \\
\hline & & & & & & \\
\hline & & & & & & \\
\hline & & & & & & \\
\hline & & & & & & \\
\hline & & & & & & \\
\hline & & & & & & \\
\hline & & & & & & \\
\hline & & & & & & \\
\hline & & & & & & \\
\hline & & & & & & \\
\hline & & & & & & \\
\hline & & & & & & \\
\hline & & & & & & \\
\hline & & & & & & \\
\hline & & & & & & \\
\hline & & & & & & \\
\hline & & & & & & \\
\hline & & & & & & \\
\hline & & & & & & 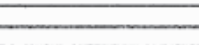 \\
\hline & & & & & & \\
\hline & & & & & & \\
\hline & & & & & & \\
\hline & & & & & & \\
\hline & & & & & & \\
\hline & & & & & & \\
\hline & & & & & 2 & \\
\hline & & & & & & \\
\hline & & & & & & \\
\hline & - & & & & & \\
\hline & & & & & & \\
\hline & & & & & & \\
\hline & & & & & & \\
\hline & & & & & & \\
\hline & & & & & & \\
\hline & & & & & & \\
\hline & & & & & & \\
\hline & & & & & & \\
\hline & & & & & & \\
\hline & & & & & & \\
\hline & & & & & & \\
\hline & & & & & & \\
\hline[ & (2) & 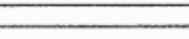 & 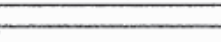 & & 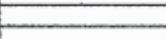 & \\
\hline 24 & 5 & 14 & 10 & 6 & 11 & 3 \\
\hline
\end{tabular}

